\title{
EL MONOPOLIO TELEVISIVO EN ITALIA \\ (EN TORNO A LA SENTENCIA NUM. 148 DE LA CORTE CONSTITUCIONAL DE 14 DE JULIO DE 1981)
}

\author{
POR \\ CARMEN CHINCHILLA MARIN. \\ Ayudante de Derecho Administrativo \\ en la Facultad de Ciencias Económicas y Empresariales \\ de la Universidad de Alcalá de Henares
}

\section{ANTECEDENTES}

Habiéndose planteado una vez más ante la Corte Constitucional italiana la duda sobre la constitucionalidad del monopolio público de la actividad radiotelevisiva a escala nacional, con la Sentencia número 148 , de 14 de julio de 1981, la Corte ha reafirmado la legitimidad constitucional del mismo, «ha salvado», por tanto, el monopolio y ha confiado al legislador ordinario su supervivencia, al poner de manifiesto la necesidad de una legislación sobre televisiones privadas que asegure el equilibrio entre el servicio público y la iniciativa privada.

La sentencia que vamos a estudiar resuelve una cuestión de constitucionalidad (questione di ligittimità costituzionale) que el Pretor de Roma (juez con competencia similar a la de nuestros jueces de Primera Instancia) planteó en el curso de un procedimiento cautelar de medidas urgentes. El órgano judicial ordinario se cuestionaba la constitucionalidad del bloque normativo que consagra el monopolio público de las transmisiones televisivas a escala nacional (arts. 1, 183 y 195 del DPR de 29 de marzo de 1973, en relación con las leyes núm. 103, de 14 de abril de 1975, y núm. 693, de 10 de diciembre de 1975) por vulnerar — según la parte que planteó la cuestión de constitucionalidad - los artículos 3 (principio de igualdad), 21 (libertad de expresión) y 43 (reserva al Estado de determinados servicios públicos) de la Constitución italiana ${ }^{1}$.

$1 \mathrm{EI}$ artículo 3 de la Constitución italiana dice:

«1. Todos los ciudadanos tendrán la misma dignidad social y serán iguales ante la ley, sin distinción de sexo, raza, lengua, religión, opción política ni circunstancias personales y sociales.

2. Constituye obligación de la República suprimir los obstáculos de orden económico y social que, limitando de hecho la libertad y la igualdad de los ciudadanos, impiden el pleno desarrollo de la persona humana y la participación efectiva de todos los trabajadores en la organización política, económica y social del país.»

El artículo 21 de la Constitución italiana, en su párrafo primero, dice:

«Todos tendrán derecho a manifestar libremente su pensamiento de palabra, por escrito y por cualquier otro medio de difusión.» 
Los hechos, brevemente expuestos, fueron los siguientes:

La Sociedad Rizzoli Editore iba a iniciar la transmisión, a través del espacio y a escala nacional, de un telediario y otros programas de televisión, utilizando para ello una red de transmisión propiedad de las Sociedades SIT, SET y Royal Editrice, compuesta por unas dieciocho estaciones instaladas por toda Italia y conectadas entre sí.

La RAI, concesionaria estatal con carácter exclusivo del servicio radiotelevisivo a escala nacional, consideró ilícita tal iniciativa y lesiva para sus intereses, ya que dichas transmisiones rebasaban el ámbito local (límite impuesto a la iniciativa privada en esta materia por la Corte Constitucional en su Sentencia 202/1976) y violaban las leyes concernientes a la reserva al Estado del servicio televisivo a escala nacional y al correlativo derecho de exclusiva de la RAI, concesionaria del servicio.

De acuerdo con lo dispuesto en el artículo 700 del Codice della procedura civile italiano, quien tenga fundados motivos para temer que, si hiciera valer su derecho en vía ordinaria, respetando los plazos establecidos para ello, estaría amenazado por un perjuicio inminente e irreparable, podrá solicitar del juez la adopción de las medidas urgentes más icóneas para asegurar provisionalmente los efectos de la decisión que recaiga en el juicio de fondo.

El artículo 701 del propio Código procesal civil distingue dos tipos de procedimiento cautelar de urgencia: 1) en vía principal -ante causamanterior a la apertura de un juicio de fondo; y 2) en vía incidental, dependiendo de un juicio de fondo. Si el procedimiento de urgencia ha sido iniciado en vía principal, la competencia corresponde al Pretor del lugar en el que el recurrente tema que vaya a producirse el hecho dañoso.

El supuesto que examinamos estaría dentro del primer tipo y, de acuerdo con el mismo, la RAI, con el fin de bloquear la invasión de las sociedades privadas en la esfera que le está reservada, solicitó del Pretor de Roma la adopción de medidas cautelares urgentes que impidieran a las sociedades demandadas llevar a cabo la iniciativa de emitir un telediario y otros programas televisivos a escala nacional.

El Pretor, con decreto de 14 de octubre de 1980, estimó la demanda y prohibió a las citadas sociedades difundir tales programas. Una vez adoptadas las medidas cautelares urgentes, tuvo lugar la comparecencia de las partes para que - a tenor de lo establecido en el art. 690 del Código procesal civil italiano- el Pretor, oyéndolas, confirmara, modificara o revocara el procedimiento adoptado. Fue en este trámite cuando las sociedades demandadas (Rizzoli y otras) formularon la cuestión de constitucionalidad de las normas reguladoras del monopolio público en materia televisiva en relación con los artículos 3, 21 y 43 de la Constitución italiana y, apoyándose en la hipotética inconstitucionalidad del bloque normativo denunciado, solicitaron

El artículo 43 de la Constitución italiana dice:

«La ley podrá, por razones de utilidad general, reservar a título originario o transmitir mediante expropiación y con indemnización al Estado, a entes públicos o comunidades de trabajadores o de usuarios determinadas empresas o categorías de empresas que exploten servicios públicos esenciales o fuentes de energía o situaciones de monopolio y tengan carácter de preeminente interés general. 
al Tribunal de Instancia que revocara el procedimiento de inhibición adoptado por el Pretor.

El Pretor, que tuvo por relevante y no manifiestamente infundada la cuestión de constitucionalidad, la planteó mediante. ordenanza de 18 de noviembre de 1980, observando previamente que el hecho de que las sociedades demandadas no tuviesen autorización administrativa para el ejercicio de las transmisiones televisivas no convertía la cuestión en irrelevante, como pretendía la RAI; la situación administrativa de las citadas sociedades no incide en el pronunciamiento del juez en la fase del juicio del artículo 700 del Código procesal civil. Tanto el Abogado del Estado como la propia Corte Constitucional en su momento declararon que en el procedimiento cautelar no era relevante la situación jurídica de las sociedades en orden al ejercicio de la actividad televisiva, por lo cual no volveremos a insistir en el tema de la autorización.

Planteada la cuestión de constitucionalidad en los términos expresados, el Tribunal de Instancia, dudando de la legitimidad de las medidas cautelares adoptadas por el Pretor, suspendió el procedimiento de urgencia y se entró en el juicio de fondo en el que se cuestionó el derecho exclusivo de la RAI a gestionar el servicio público radiotelevisivo a escala nacional $\mathrm{y}$, por tanto, la legalidad de la medida inhibitoria; por todo lo cual el juez se reservaba su potestad de confirmación, modificación o revocación para el momento en que el Alto Tribunal hubiese resuelto la cuestión de constitucionalidad.

Ya en el juicio de fondo el Tribunal planteó las cuestiones que la Corte tendría que valorar para decidir sobre la constitucionalidad o inconstitucionalidad de las normas denunciadas.

El primer tema planteado es el del fundamento constitucional del monopolio. Dada la limitación de frecuencias disponibles y el alto coste de las instalaciones, se establece el monopolio del Estado en esta materia para garantizar la libertad de expresión consagrada por el artículo 21 de la Constitución italiana, para «salvarla» del peligro de un monopolio u oligopolio privado. Planteado así el problema, la argumentación se movería entre dos términos: el primero relacionado con la libertad de expresión para cuya garantía se establece el monopolio, y el segundo referente a las condiciones técnicas que justifican dicha institución como medio de defensa frente al monopolio privado $u$ oligopolio.

La limitación de frecuencias y el alto coste de las instalaciones son datos de hecho verificables. El Pretor entendió que de la documentación presentada por las sociedades demandadas podría «deducirse tazonablemente» que la situación de hecho en que la Corte Constitucional apoyaba sus decisiones precedentes había cambiado como consecuencia del progreso técnico, en el sentido de que la técnica permitía ahora, dentro de unos límites bastante amplios, el acceso de las sociedades privadas a los instrumentos de transmisión a través del espacio.

Ya que el monopolio se justifica por la limitación de frecuencias y el alto coste de las instalaciones, en cuanto que garantiza la libertad de expresión, si estos datos técnicos cambiasen, podría también cambiar el juicio sobre la función del monopolio público de la información y, en consecuencia, el juicio sobre la legalidad de las normas que lo amparan. En este sentido, si 
la limitación de frecuencias ya no es tal y los costes no son excesivos, no puede mantenerse que sean constitucionales las normas restrictivas de la iniciativa privada en esta materia, que pretenden fundamentarse en el artículo 43 de la Constitución.

La Corte Constitucional, según el Tribunal de Instancia, debería valorar si y en qué medida una realidad tecnológica distinta de la antetior puede incidir en el juicio sobre la legitimidad constitucional de las normas que reservan al Estado el monopolio público de las transmisiones televisivas a escala nacional.

La segunda cuestión que el Alto Tribunal ha de plantearse es si las normas impugnadas vulneran el artículo 3 de la Constitución italiana (principio de igualdad), ya que de hecho se da una situación de privilegio, tanto en favor del Estado como de las televisiones extranjeras que pueden emitir en todo el territorio nacional (la Sentencia 225/1974 declaró inconstitucional la extensión del monopolio a actividades relacionadas con repetidores de emisoras extranjeras que no operan sobre canales nacionales).

Por último, la Corte Constitucional debería valorar la constitucionalidad del bloque normativo denunciado en relación a las transmisiones efectuadas por emisoras locales a todo el territorio nacional mediante su interconexión (como se recordará, la Rizzoli iba a emitir un telediario y otros programas mediante la unión de varias estaciones locales).

Pasamos, pues, a ocuparnos del estudio de estas cuestiones a la luz de las alegaciones presentadas por las partes respecto a cada una de ellas.

\section{LA CONSTITUCIONALIDAD O INCONSTITUCIONALIDAD DEL MONOPOLIO}

\section{Monopolio y libertad de expresión}

El artículo 21 de la Constitución italiana consagra «el derecho» de todos a manifestar su pensamiento a través de cualquier medio de difusión. Cuando el medio de difusión es la televisión, ese derecho de todos - por razones técnicas referentes a las frecuencias y al coste de las instalaciones- corre el peligro de convertirse en el derecho de muy pocos. Por ello, como garantía de la libertad de expresión, se ha instituido el monopolio público de la actividad radiotelevisiva. Sobre esta argumentación en defensa de la legalidad constitucional del monopolio, la RAI y las sociedades privadas por ella demandadas presentaron alegaciones que, bajo el común denominador de la defensa de la libertad de expresión, sirvieron de fundamento a posiciones de signo contrario. Mientras que para las sociedades demandadas el monopolio no sólo no es necesario para garantizar la libertad de expresión, sino que, además, restringe esta libertad, la RAI, por el contrario, considera que el monopolio no sólo garantiza dicha libertad, sino que constituye el único medio de garantizarla.

La Rizzoli y demás sociedades demandadas cuestionan que el monopolio público sea necesario para garantizar la libertad de expresión acudiendo al concepto de «pluralismo natural» que existiría desde el momento en que las posibilidades de utilizar el espacio aéreo fueran (como lo son para estas so- 
ciedades) muy amplias y, por tanto, los sujetos que tuvieran acceso a él fuesen muchos. En este caso no se vulneraría la libertad de expresión porque el respeto de esta libertad exige solamente que todos los que tengan la posibilidad de disponer de un medio idóneo puedan utilizarlo para difundir su pensamiento. Si existe la posibilidad de un «pluralismo natural», el alcanzado a través del monopolio estatal sería contrario a dicha libertad.

Es importante, pues, determinar qué se entiende por libertad de expresión y sobre todo cuál es la extensión de la garantía consagrada por el artículo 21 de la Constitución italiana. Si para las sociedades demandadas el respeto de esta libertad exige solamente que todos los que dispongan de un medio de difusión puedan utilizarlo para manifestar su pensamiento, para la RAI lo que garantiza el artículo 21 es la libertad de expresión en su contenido, independientemente de los modos y medios de difusión y de la abstracta disponibilidad por todos de estos medios.

Este es también el criterio de interpretación que utiliza el Abogado del Estado en defensa del monopolio cuando afirma que no puede haber una garantía absoluta e incondicional respecto del uso de los medios de difusión. Este uso y la reserva del Estado tienen que ser compatibles de acuerdo con lo establecido en el artículo 21, que no puede garantizar en idéntica medida y del mismo modo el uso de todos los medios de difusión.

Para las sociedades privadas demandadas el monopolio no. sólo restringe la libertad de expresión, sino que también daña el pluralismo informativo y cultural. Por el contrario, para la RAI la pretendida inconstitucionalidad del monopolio público sería infundada, porque sólo éste garantiza efectivamente tanto la libertad de expresión como el pluralismo, la independencia y la objetividad de la información. En este sentido afirma que la teledifusión nacional, declarada servicio público por la Ley número 103 de 1975 , puede garantizar las exigencias de pluralismo, independencia, objetividad y cumplimiento de los objetivos culturales y sociales del servicio público de televisión. Estos objetivos estarían garantizados por el monopolio estatal, pero no podría exigirse, en cambio, su observancia a las televisiones privadas.

\section{Monopolio y principio de igualdad}

El bloque normativo denunciado por las sociedades privadas vulneraba, a su juicio, el principio de igualdad consagrado en el artículo 3 de la Constitución italiana, y ello porque las citadas normas llevan a una situación de privilegio para el Estado y las emisoras extranjeras. En este sentido, las sociedades denunciaron el excesivo número de frecuencias asignadas al Estado, que además de ser muchas no se utilizan todas.

Respecto al tema de la asignación de frecuencias, las sociedades denunciaron la inconstitucionalidad del D.M. de 3 de diciembre de 1976 (relativo a la asignación de frecuencias a escala nacional), por considerar que la Administración ejercita tal potestad con absoluta discrecionalidad. La RAI opuso a este argumento que la asignación de frecuencias se rige por normas internacionales y que se efectúa de acuerdo con el citado Decreto.

De todas formas, no es necesario extenderse más en esta cuestión, ya que el segundo apartado del fallo de la Sentencia contiene la declaración de 
inadmisibilidad de la referida cuestión, porque la parte que la había planteado se limitó a enunciar esa discrecionalidad y no motivó la relevancia de la misma ni que la cuestión no estuviese manifiestamente infundada, elementos ambos indispensables para promover juicio incidental de constitucionalidad de las leyes.

Así pues, volviendo al tema que nos ocupa, las normas denunciadas vulnerarían el artículo 3, de un lado, por la discriminación que supone la reserva al Estado de un gran número de frecuencias y, de otro, por la determinación del ámbito de utilización de las mismas, ya que mientras las emisoras locales se ven obligadas a transmitir en un ámbito limitado, la sociedad concesionaria estatal y las emisoras extranjeras pueden hacerlo libremente en todo el territorio nacional.

Frente a esta postura, la RAI argumentó que la situación de la empresa concesionaria estatal y de las emisoras locales no es comparable con la de los repetidores de emisoras extranjeras debido a la especial disciplina que regula a éstas.

\section{Monopolio y servicios esenciales}

La teledifusión en Italia es un servicio público esencial de preeminente interés general. Para afrontar los distintos problemas que plantea la disciplina de la actividad radiotelevisiva es preciso considerar la cuestión del servicio público, ya que la calificación de «público» y «esencial» confiere al servicio unas características absolutamente peculiares.

Las sociedades que plantearon la cuestión de constitucionalidad alegaron que las normas reguladoras del monopolio de televisión vulneraban también el artículo 43 de la Constitución italiana (reserva al Estado de determinados servicios públicos). Según el citado artículo, la ley puede reservar determinados servicios públicos de interés preeminente al Estado. Y esto fue lo que hizo la Ley de 14 de abril de 1975, que calificó la difusión radiofónica y televisiva como servicio público de interés preeminente general en el sentido del artículo 43 de la Constitución, en cuanto que sirve para ampliar la participación del ciudadano y contribuye al desarrollo social y cultural del país conforme a los principios consagrados en la Constitución. El servicio -establece el art. 1 de la Ley- está, por tanto, reservado al Estado.

Las sociedades privadas demandadas invocaron, en apoyo de su pretensión, la propia jurisprudencia constitucional. La Corte, en su Sentencia número 225/1974, declaró que subsistían todavía las razones de utilidad general que justifican la reserva del servicio televisivo al Estado a tenor de lo establecido en el artículo 43 de la Constitución italiana, pero que era, en cambio, inconstitucional su amplitud actual: concretamente su extensión a la actividad de los repetidores extranjeros y de las emisoras privadas a escala local. El Alto Tribunal identifica la utilidad general con la necesidad de garantizar la objetividad y la imparcialidad en el uso del medio de difusión más importante, en cuanto que tales condiciones podrían verse comprometidas dada la limitación de frecuencias y el alto coste de las instalaciones. En tal sentido, las sociedades privadas argumentaron que, si las condiciones técnicas que ponen en peligro ese fin de utilidad general habían cambiado, 
habrian desaparecido asimismo los motivos de utilidad general y, por tanto, también debería cambiar la decisión de la Corte Constitucional en cuanto al mantenimiento del monopolio. $Y$ en este sentido, recuerdan las sociedades demandadas, se pronunció el Alto Tribunal cuando excluyó del monopolio las actividades de los repetidores extranjeros y de las emisoras privadas a escala local. Para las sociedades demandadas sería contradictorio mantener el monopolio estatal y excluirlo a nivel local.

En contra de las alegaciones de las sociedades privadas, para las que la reserva al Estado del servicio público de teledifusión vulneraría el artículo 43 de la Constitución italiana por no existir ya las razones de utilidad general que lo justifican, la RAI defendió que la teledifusión es un servicio público esencial de preeminente interés general y que, subsistiendo las razones de utilidad pública a las que se refiere el artículo 43 , su reserva al Estado es constitucional. La razón de utilidad general es fundamentalmente la necesidad de evitar la concentración oligopolística de las emisoras. La RAI estima que la libertad de antena en un ámbito superior al local se transformaría inevitablemente en un poder privado más peligroso aún que un análogo poder público. Los empresarios más fuertes lucharían por la conquista del mercado, aprovechando su mayor poder económico y excluyendo, antes o después, la concurrencia de los empresarios pequeños.

Por último, la Rizzoli y demás sociedades se refirieron a la Prensa y al Cine, medios de difusión éstos para los que no se concibe el monopolio público de su gestión, argumentando que si la Ley de 1975 declaró que la radiodifusión es un servicio público de preeminente interés general, .que, «por tanto», está reservado al Estado, con tal criterio se está abriendo. la puerta a la reserva por el Estado de otros medios de comunicación social como los citados. La defensa de la RAI puso de relieve los puntos de diferenciación entre la prensa y la televisión, por lo que no se puede extender la reserva monopolística a aquélla. Tales datos diferenciadores son, entre otros, la menor difusión de la prensa, la diversidad del medio de comunicación y la materialidad del vehículo que, tratándose esencialmente de imágenes, puede tener efectos más penetrantes y acríticamente recibidos que la palabra escrita. Estos argumentos están reforzados por la expresa mención del artículo 21 de la Constitución italiana acerca de la prensa.

De lo dicho hasta ahora se deduce que en el tema del monopolio y los servicios esenciales es capital definir qué ha de entenderse por «razones de utilidad pública», ya que, si subsisten tales razones, la reserva se justifica en el sentido del artículo 43; por el contrario, si han desaparecido (como argumentan las sociedades demandadas por la RAI), tal reserva sería inconstitucional.

La Corte Constitucional, como se recordará, identifica la utilidad pública con la necesidad de garantizar la objetividad y la imparcialidad en el uso de la televisión, en cuanto que la limitación ;e frecuencias y el alto coste de las instalaciones podrían ponerlas en peligro. Para las sociedades privadas las condiciones técnicas han cambiado, y no es necesario, por tanto, garantizar la objetividad y la imparcialidad, ya que éstas no se verían entonces comprometidas; habrían desaparecido, por tanto, las razones de utilidad general. 
Por el contrario, para la defensa de la RAI, las razones de utilidad general subsisten porque es necesario evitar la tendencia a la concentración oligopolística de las emisoras que existen mientras permanezcan las condiciones técnicas de limitación de frecuencias y el alto coste de las instalaciones.

Por todo ello, se trata ahora de afrontar la cuestión de si se dan o no las condiciones técnicas necesarias para la existencia del monopolio, tema éste de capital importancia en el desarrollo de la Sentencia que nos ocupa.

La defensa que las sociedades privadas hicieron de su pretensión consistió fundamentalmente en ofrecer un contra-argumento técnico tendente a demostrar que los presupuestos tecnológicos habían cambiado. Se dijo que la disponibilidad actual de las frecuencias utilizables para transmisiones por ondas era de tal amplitud a escala nacional que no supondría limitación alguna a la libertad de expresión.

Añadió la defensa de dichas sociedades que no se daban ya las condiciones de limitación de frecuencias y que esto quedaría demostrado por las numerosas emisoras de ámbito nacional existentes en la actualidad (además de la RAI, Montecarlo, Suiza, Francia y Capodistria). Todo ello aparte de las posibilidades que ofrece la transmisión por satélite.

En lo referente al coste de las instalaciones y del mantenimiento, se alegó que tampoco aquél justificaría el monopolio, porque el coste de instalaciones que alcancen una vasta cobertura del territorio nacional sería de unos quince mil millones de liras, «soportable para cualquier empresa», y el de mantenimiento sería inferior al de un periódico.

Precisamente la utilización de emisoras locales conectadas entre sí viene a reforzar este argumento. La conexión de varias emisoras locales para la difusión de un mismo programa ofrece unas posibilidades de utilización sin límites a un costo bajísimo. Se puede conseguir fácilmente una multiplicidad de redes de unión (mediante puentes-radio), y con un número relevante de este tipo de redes y el bajo coste de su instalación y mantenimiento estaría garantizado el pluralismo de la información y quedaría excluida la posibilidad de que se formara un oligopolio.

Lógicamente, la defensa de la RAI esgrimió el argumento contrario, insistiendo en la limitación de frecuencias y reconociendo como excepción las posibilidades que ofrece el satélite, aunque para su utilización habría que esperar muchos años.

A esto añadió que son tantas las emisoras privadas que hoy funcionan en Italia que no pueden instalarse más redes nacionales ni regionales. En todo caso, para que fuera válido el argumento del Tribunal de Instancia sobre el elemento técnico de la supuesta evolución de las condiciones de la disponibilidad de los canales sería necesario, según la defensa de la RAI, que tal afirmación estuviese probada en el sentido de que los datos sean ciertos y no simplemente probables o razonables. La RAI insiste en que continúan existiendo las condiciones técnicas que han inspirado hasta ahora las decisiones del Alto Tribunal. En esta misma línea se sitúan los argumentos técnicos del Abogado del Estado, quien consideró que la limitación de canales no permitía la proliferación de redes por ondas con carácter nacional, y cuestionó el hecho de que efectivamente puedan multiplicarse las posibilidades de transmisión a escala nacional a través de la conexión de emisoras 
locales, ya que su coste sería importante $y$, por tanto, soportable únicamente por un limitado número de sujetos.

Por último, dentro de este bloque de razonamientos en torno al tema de las frecuencias, el Abogado del Estado introdujo un nuevo argumento, que vino a alterar los términos en los que hasta ahora había sido planteada la cuestión. Ese nuevo elemento consiste en la superación del valor determinante y exclusivo de los factores técnicos justificadores de la legalidad del monopolio, en favor de un elemento jurídico cual es el carácter de servicio público de utilidad general de la radiotelevisión: «de la evolución de la jurisprudencia constitucional —afirma el Abogado del Estado- es lícito deducir que ha sido superada esta perspectiva exclusiva, ya que la Corte ha reconocido que la actividad de televisión atiende a un servicio público esencial y que esta condición, unida al fin de utilidad general al que esta actividad sirve, justificaría autónomamente la institución del monopolio público a la luz del artículo 43 de la Constitución». De la trascendencia de esta afirmación nos ocuparemos más adelante.

\section{Monopolio e interconexiones de emisoras locales}

La última cuestión que la Corte Constitucional hubo de plantearse es la referente a las emisiones realizadas a través de la conexión de varias cadenas locales: ¿Se extiende el monopolio a esta actividad o, por el contrario, es constitucional la conexión de emisoras locales?

En favor de la legalidad de tal conexión se argumentó que no transformaría las emisoras locales en emisoras supralocales o nacionales, ya que se trataría solamente de difundir en varias ciudades un mismo programa, manteniendo cada emisora su individualidad, autonomía y zona de competencia. No sería inconstitucional dicha conexión porque estaría amparada por la libertad de circulación de programas televisivos en territorio nacional a través de repetidores, independientemente de la disponibilidad de frecuencias.

Para la RAI, por el contrario, es legítima la prohibición de esas conexiones, ya que ésta no es más que una forma de transmitir para ámbitos superiores a los permitidos, eludiendo, además, la necesaria concesión gubernativa.

Para el Abogado del Estado, el tema se sitúa bajo el mismo prisma del concepto de servicio público que justifica el monopolio $\mathrm{y}$, por tanto, las conexiones serían inconstitucionales.

\section{LA DOCTRINA DE LA CORTE CONSTITUCIONAL}

La Corte, en vista de todos estos argumentos, esgrimió una serie de consideraciones de derecho que la llevarían a declarar infundada la cuestión de constitucionalidad planteada y, por tanto, declara la legitimidad constitucional del monopolio público de la teledifusión.

Como se recordará, el Tribunal de Instancia planteó la cuestión de constitucionalidad en base a los cambios tecnológicos sobrevenidos, en presencia de los cuales no se daría ya la limitación de frecuencias ni sería tan alto el 
coste de las instalaciones, razones que hasta ahora habian servido de fundamento a las argumentaciones del Alto Tribunal en la materia. Según el Tribunal de Instancia, la nueva situación justificaría suficientemente la duda sobre la constitucionalidad de las normas denunciadas.

Después de una detallada referencia a la jurisprudencia constitucional en la materia (Sentencias 59/1960, 225/1974, 226/1974 y 202/1976), se sostuvo que el servicio público esencial de radioteletransmisión a escala nacional puede ser reservado al Estado en razón del fin al que sirve: evitar la concentración de la actividad radiotelevisiva en un monopolio $u$ oligopolio privado. A continuación, refiriéndose a la necesidad de evitar tal concentración, la Corte hace una afirmación de gran trascendencia: «esta necesidad no se presenta sólo en relación a la mayor o menor disponibilidad de frecuencias de transmisión, sino que resulta además de la naturaleza misma del fenómeno de la tadioteletransmisión, contemplado dentro del contexto socioeconómico en el que está destinado a desenvolverse». Este contexto socioeconómico al que el Alto Tribunal se refiere es el que crea el sistema de economía libre de mercado. Dado el limitado número de frecuencias disponibles y el alto coste de las instalaciones, no podría darse en el mercado de estos bienes la libre concurrencia. Por el contrario, serían muchos los demandantes y pocos los ofertantes, lo que explica esa tendencia irremediable al oligopolio de oferta.

Se sostuvo que el aumento del número de frecuencias disponibles no es un elemento determinante que excluya el peligro del oligopolio privado, porque, debido a los factores económicos a los que acabamos de referirnos, los riesgos de concentración oligopolística siguen existiendo, y sólo podrían evitarse proveyendo al sector radiotelevisivo de una sólida barrera antitrust. La Sentencia 202/1976 había señalado al legislador la necesidad de una regulación de televisiones privadas que asegurara el equilibrio entre el servicio público y la iniciativa privada. En este sentido, ante la persistente inercia del legislador, la Corte Constitucional vuelve a recordar la necesidad de dicha reglamentación.

Se consideró que no es contradictoria la exclusión del monopolio estatal en las transmisiones locales. Dadas las peculiaridades de la televisión, las emisoras locales pueden ejercer la actividad televisiva sin producir las consecuencias dañosas que se derivan del mismo ejercicio a escala nacional. A nivel local concurren una pluralidad de emisoras de muy diferentes orientaciones. A escala nacional se le atribuiría al sujeto privado operante en régimen de monopolio u oligopolio una potencial capacidad de influencia incompatible con las reglas del sistema democrático. Esa capacidad potencial vulneraría por sí sola el artículo 21 de la Constitución italiana, invocado precisamente como tesis en favor de la abolición del monopolio, ya que semejante situación de preeminencia de un sujeto o de un grupo privado no podría dejar de reprimir la libertad de expresión de todos aquellos que, por no disponer del necesario poder económico o técnico, verían reducido el ámbito de ejercicio de su libertad.

Las normas denunciadas no vulneran, por tanto, el artículo 21 de la Constitución italiana, del mismo modo que no vulneran tampoco el artículo 3 , ya que no se pueden comparar las situaciones de la sociedad conce- 
sionaria del servicio público y de los repetidores de emisoras extranjeras y la de las emisoras privadas.

El de las emisoras extranjeras es un fenómeno absolutamente particular. La decisión de la Corte (Sentencia núm. 225/1974) de declarar inconstitucional la extensión del monopolio a la actividad de los repetidores de estaciones extranjeras se inspiró en la especificidad de dicho sector, ya que la reserva estatal hubiese producido en este caso una especie de «autarquía nacional de las fuentes de información», contratia a la exigencia de libre circulación de ideas en el ámbito internacional. Debido a esta singularidad quedaría excluida aquí la operatividad del principio de igualdad.

Por último, el Alto Tribunal analizó el problema de la conexión de emisoras locales, con la que, a su juicio, se consigue emitir para la totalidad del territorio nacional, ámbito éste reservado al Estado. Por todo lo cual, la solución de la cuestión planteada vendría dada por todo lo dicho en favor de la legalidad constitucional de la reserva al Estado de las transmisiones a escala nacional. La Corte hace una precisión cuando dice que la inconstitucionalidad de las emisiones así obtenidas quedará limitada a la hipótesis de que la conexión posibilite una transmisión que traspase los límites establecidos por la Sentencia número 202/1976, quedando los demás aspectos del fenómeno (medios utilizados, ámbito y modalidades de ejercicio) a la espera de una reglamentación más adecuada.

\section{CONCLUSIONES}

La Sentencia número 148/1981 de la Corte Constitucional, de cuyo contenido acabamos de dar cuenta, nos parece de un interés primordial no sólo porque ha confirmado la legalidad constitucional del monopolio de la actividad televisiva a escala nacional, punto éste en el que la Sentencia no es nada innovadora, sino sobre todo porque se ha separado del que hasta ahora fue el argumento básico de sus decisiones en la materia (la limitación de frecuencias y el alto coste de las instalaciones), para utilizar ahora un esquema de razonamiento fundado en la noción de la televisión como servicio público esencial y haciendo hincapié en los elementos necesarios según el artículo 43 de la Constitución italiana para establecer la reserva a favor del Estado.

La Corte había utilizado como argumento para defender la constitucionalidad del monopolio público el dato del limitado número de frecuencias disponibles. En la Sentencia número $225 / 1974$ había introducido además el razonamiento basado en el concepto de servicio público esencial, aunque poniéndolo en una posición subordinada respecto del referido a la limitación de canales.

A partir de este momento, sus decisiones se fundamentaron en una doble motivación (es lo que Zaccaria llama doppio binario en la motivación: monopolio de hecho y servicio público esencial) ${ }^{2}$. La Corte ha ido superando el peso exclusivo que tenía la perspectiva técnica en el problema.

2 Zaccaria, La Corte cambia strada: il monopolio radiotelevisivo è legittimo solo a metà, en «II diritto delle radiodiffusioni e delle telecomunicazioni», núm. 2, 1976. 
En la Sentencia que nos ocupa, se ha restado importancia al argumento técnico a la hora de pronunciarse sobre la legitimidad del monopolio, apoyando desde ahora el razonamiento en el argumento jurídico del servicio público esencial que es la televisión. Es decir, en cuanto que la actividad televisiva tiene ese carácter, puede ser reservada al Estado por razones de utilidad pública, y esta tazón es por sí sola suficiente para que el monopolio público esté legitimado constitucionalmente conforme al artículo 43 de la Constitución.

Es además importante destacar cómo en sus consideraciones de derecho la Corte Constitucional insiste - como antes lo hicieron la defensa de la RAI y el Abogado del Estado- en la subsistencia de la utilidad general como razón justificadora de la legitimidad del monopolio, siguiendo de cerca, a nuestro juicio, lo que Zaccaria había señalado en 1976 en el sentido de que el Alto Tribunal debía abandonar de una vez por todas la línea de la doble motivación y utilizar el argumento de servicio público, insistiendo no tanto en el «preeminente interés general» (noción objetivamente más ligada a características del servicio que a su organización y, por tanto, difícilmente invocable con referencia al distinto ámbito, nacional o local), como en la noción de «utilidad general» que, aunque ligada a valoraciones de tipo político, contiene elementos susceptibles de ser fiscalizados por la jurisdicción constitucional ${ }^{3}$.

Con la presente Sentencia -utilizando la expresión de Chiola ${ }^{4}$ - se ha «desanclado» la legitimidad de la reserva de las conquistas tecnológicas, porque el peligro del oligopolio permanece y sólo puede desaparecer si se establece para el sector radiotelevisivo una legislación antitrust. Efectivamente, es de la propia naturaleza del fenómeno radiotelevisivo y del contexto socioeconómico en el que ha de desarrollarse, de donde surge la tendencia al monopolio o al oligopolio privado.

Cuando el Tribunal Constitucional italiano insta al legislador a que apruebe una legislación antitrust en materia radiotelevisiva no está dejando la puerta abierta al replanteamiento de la legitimidad constitucional de la reserva estatal. La Sentencia ha salvado al monopolio, y lo que hace es precisamente confiar su supervivencia al legislador.

No se trataría tampoco de garantizar el «pluralismo privado» como alternativa al monopolio público. Desde un punto de vista funcional, la televisión es un instrumento para informar a la sociedad, con lo que la actividad noticial sería un servicio público esencial caracterizado por la nota de «alteridad» del interés gestionado. Es cierto que la objetividad de la información ha de pasar por el pluralismo de las voces noticiales, pero ello no implica que éstas deban ser gestionadas por particulares.

En lo que se refiere concretamente a la disciplina antitrust que se reclama del legislador, Paladin ${ }^{5}$ considera que es el momento del otorgamiento de

3 Zaccaria en el trabajo citado anteriormente.

4 Chiola, Il pluralismo privato garantito quale altenativa al monopolio statale della radiotelevisione, en «Il diritto delle radiodiffusioni e delle telecomunicazioni», núm. 3, 1981.

5 Paladin, Stato e problemi delle diffusioni radiotelevisive private, en «Il diritto delle radiodiffusioni e delle telecomunicazioni», núm. 1, 1981. 
la autorización aquel en el que el legislador ha de concentrar su atención a la hora de establecer las medidas tendentes a evitar el monopolio u oligopolio privado. El citado autor ofrece las que a su juicio serían esas medidas:

«En vía preventiva es preciso establecer un límite a las autorizaciones otorgadas a un mismo sujeto y paralelamente habría que afrontar de nuevo el problema del 'empresario oculto', imponiendo a las empresas radiotelevisivas privadas unas características adecuadas para asegurar su transparencia.

En vía sucesiva habría que frenar la tendencia a la concentración, las conexiones y las uniones de todo tipo.»

Esta última afírmación nos lleva a plantearnos la cuestión de la conexión de emisoras locales sobre la que la Corte Constitucional se ha pronunciado en la Sentencia que estamos analizando.

El Tribunal Constitucional italiano declaró que toda transmisión que excede de los límites impuestos por la Sentencia número 202/1976 es ilícita porque invade la reserva del Estado, pero insiste en que el relieve constitucional de la cuestión se limita a esa hipótesis, debiendo regular el legislador los distintos aspectos del fenómeno como son los medios utilizados, el ámbito y las modalidades de su ejercicio.

Podría objetarse que el reconocimiento de un derecho de libertad para transmitir programas en el ámbito local legitima las transmisiones obtenidas por la acumulación de varias manifestaciones idénticas; legitima, por tanto, un resultado que se prohíbe a quien pretende crear una red alternativa a la estatal. $Y$ todo ello en base a que cada una de esas transmisiones estaría dentro de la libertad de expresión que el artículo 21 de la Constitución italiana garantiza. A este respecto, Chiola añade que eso sería cierto sólo cuando cada transmisión pueda incluirse en el concepto de libertad de expresión, es decir, cuando esas transmisiones puedan ser consideradas como manifestaciones del pensamiento. En este sentido, el transmitir una obra de otros quedaría fuera de dicha libertad porque la garantía que presta el artículo 21 se circunscribe a la «propiedad» de la manifestación, mientras que la mera reproducción del pensamiento de otros termina por invadir la esfera de la «difusión del pensamiento», que sólo debe garantizarse a su autor.

Sin embargo - seguimos con el argumento de Chiola - cuando el mismo programa transmitido al mismo tiempo por varias emisoras sea el resultado de una coproducción y sea asimilable por tanto a una obra colectiva, su difusión a un área superior a la local no podría considerarse ilegal. Esta última sería la que Zagrebelsky ${ }^{6}$ llama «interconexión funcional u objetiva» (referida a la producción y programación radiotelevisiva) distinta de la interconexión subjetiva, objeto de nuestro estudio (formación de redes alternativas resultantes de la coordinación de la actividad de una pluralidad de estaciones locales). El legislador podría evitarlo prohibiendo la simultaneidad de la emisión del programa.

6 Zagrebelsky, Collegamenti, interconnessioni e concentrazioni fra le emittenti in ambito locale, en Radiotelevisione pubblica e privata in Italia, a cura di Paolo Barile, Enzo Cheli e Roberto Zaccaria, Il Mulino, 1980. 
En todo caso, mientras continúe existiendo el vacío legislativo, estamos de acuerdo con Chiola en que las conexiones de varias emisoras privadas son inconstitucionales, porque si el objeto de la exclusiva del Estado es la emisión radiotelevisiva a escala nacional, cualquier transmisión que, a través de la citada conexión, obtenga una audiencia de dimensión nacional viola la reserva.

Contemplados ya los problemas de fondo planteados en esta cuestión de constitucionalidad, sólo nos queda llamar la atención sobre la importancia que tiene el simple hecho de que la Corte Constitucional haya dictado una Sentencia más en el sector de la radio y la teledifusión que, como se sabe, ha dado lugar en Italia a una inversión de las funciones que normalmente corresponden al Parlamento y al Tribunal Constitucional italianos.

Ante la inercia del legislador, la Corte Constitucional ha dictado las llamadas «Sentencias-ley», mediante las que ha establecido los principios orientadores reclamando del Parlamento su actuación. Desde que el Alto Tribunal - con las importantes Sentencias de 1974 y 1976 - se plantea la constitucionalidad de la extensión del monopolio y empieza a excluir determinados sectores de la reserva estatal, empiezan a surgir problemas cuya solución compete al legislador. Este vacío legislativo va a provocar además que en este proceso, que Paladin ${ }^{7}$ califica de largo y tortuoso, varios jueces se hayan rebelado contra la Corte; y de estas manifestaciones de «sublevación» por parte de los jueces, la más importante ha sido precisamente la ordenanza del Pretor de Roma, en la que plantea la cuestión de constitucionalidad resuelta por la Sentencia que nos ocupa. Como se recordará, el Pretor razonó que, debido al cambio de la situación tecnológica, la posición de privilegio de la RAI supone una evidente e irrazonable disparidad de tratamiento, por lo que una serie de disposiciones del Código Postal y de la Ley número 103 de 1975 serían inconstitucionales porque establecen el monopolio público de las transmisiones a escala nacional.

El Alto Tribunal no podía resolver con su Sentencia todos los problemas planteados, ni siquiera la mayor parte de ellos, pero es importante - como señala Paladin - que no puede justificarse ya la inercia de las fuerzas políticas y del Parlamento.

En un intento de buscar una posible conexión entre la situación italiana (a propósito de las relaciones Parlamento/Corte Constitucional en el sector radiotelevisivo) y la española, pensamos que la cuestión, tal y como se plantea en Italia - donde la situación radiotelevisiva ha sido calificada por algunos autores (Caretti, Cheli y Zaccaria) ${ }^{8}$ de «casi total anarquía»-, no puede trasladarse a nuestro país.

Ahora bien, de la jurisprudencia de nuestro Tribunal Constitucional puede deducirse razonablemente que éste no va a suplir la función del legislador en esta materia (Sentencias de 31 de marzo de 1982 y de 7 de diciembre de 1982). El Tribunal ha declarado: «Adoptar el sistema de gestión indirecta requiere una decisión y un desarrollo legislativo que este Tribunal no puede

7 Paladin en el mismo trabajo citado en páginas anteriores.

8 Caretti, Cheli y Zaccaria, Tendenza evolutive nei modelli radiotelevisivi e compiti del legislatore, en «Il diritto delle radiodiffusioni e delle telecomunicazioni», núm. 3, 1981. 
suplir.» $\mathrm{Ha}$ estimado en ambas Sentencias que la televisión privada no está necesariamente impuesta por la Constitución ni tampoco constitucionalmente impedida, sino que se trata de una opción política que puede adoptarse por la vía de una ley orgánica.

El Tribunal ha dejado claro que la decisión de adoptar la forma de gestión privada del servicio público radiotelevisivo corresponde al legislador y no a aquél. Ahora bien, en ningún momento puede deducirse de ello que el Alto Tribunal esté requiriendo al legislador para que entre a regular dicha materia. No existe en nuestro país la situación de urgente necesidad de regulación de la televisión privada que se da en Italia, como tampoco parece que vayamos a tener «Sentencias-ley» similares a las de la Corte Constitucional italiana. 